\title{
Reescrever a história para a dignidade humana'
}

\section{- Rewriting history for the human dignity}

\author{
Rosângela de Lima Vieira \\ "Desistir... eu já pensei seriamente nisso, mas nunca me levei realmente a sério; \\ é que tem mais chão nos meus olhos do que o cansaço nas minhas pernas, \\ mais esperança nos meus passos, do que tristeza nos meus ombros, \\ mais estrada no meu coração do que medo na minha cabeça."
}

Cora Coralina

Resumo: A proposta do artigo consiste inicialmente em refletir sobre as transformações pelas quais passou a história enquanto área do conhecimento e como seu processo de ampliação do objeto de estudo, do conceito de sujeito histórico e das múltiplas temporalidades transformou nossa percepção de ação pedagógica. Em seguida utilizamos essas novas posturas da Nova História, e nela o legado de Fernand Braudel, para pensar a contribuição da área de história na construção da dignidade humana. Ilustramos nossa argumentação com duas estruturas históricas de longa duração: o machismo e o racismo. Assim, foi possível apontar, para a dignidade humana, a condição de sujeito histórico individual e coletivamente consciente das possibilidades de mudanças e permanências históricas.

Palavras-chave: Nova História. Estruturas históricas. Sujeito histórico. Machismo. Racismo.

1 Dedico esse texto a todas e todos que, tendo estado na situação de minha aluna e de meu aluno, compreenderem e me fizeram compreender também que escolhemos todos os dias sermos sujeitos de nossas vidas e das outras pessoas, no curto espaço da nossa ação nas estruturas históricas.

2 Doutorado em História, Pós-doutorado em Economia, docente do departamento de Ciências Políticas e Econômicas FFC - Universidade Estadual Paulista. Programa de Pós-Graduação em Ciências Sociais e do Programa Mestrado Profissional em Sociologia. rosangela.vieira@unesp.br 


\begin{abstract}
The proposed article consists initially in reflecting on the transformations in which history, as an area of knowledge, went through and how its object of study ampliation process, from concept of historical subject and the multiple temporalities transformed our perception in pedagogic action. Next we utilize these new postures of New History, and in it the legacy of Fernand Braudel, to think the contribution of the area of history in the construction of human dignity. We illustrate our argument with two historic structures of long duration: sexism and racism. This way, was possible to point, for human dignity, the condition of individual historic subject and collectively conscient of the possibilities of historic changes and permanences.
\end{abstract}

Keywords: New History. Historic structures. Historical subject. Sexism. Racism.

\title{
Introdução
}

A conjuntura da pandemia de Covid-19 traz para mim um duplo sentimento paradoxal: ao mesmo tempo em que a situação de stand by de muitos projetos nos coloca em suspensão, também um sentido de urgência aflorou diante do perigo iminente, da consciência da fragilidade e da finitude. Esses sentimentos se definem como a busca de prioridade, seja por aceitar o isolamento social por um lado, seja por averiguar o que realmente queremos deixar para as novas gerações. Nesse sentido, uma pergunta se impôs: qual o legado da professora de história?

Dentro dessa conjuntura e desses sentimentos me sinto instigada pela proposta de pensar na contribuição da área de história para a construção da dignidade humana em conjuntura de pandemia. Desse modo, aponta-se para mim uma tarefa complexa, mas também agradável. Permite refletir sobre a função social e política da história e da historiografia. Isto porque é possível refazer o caminho de autorreflexão do métier do historiador. Percurso que já fiz algumas vezes, dada meus interesses acadêmicos, mas que agora ganham muito mais significado.

O termo história apresenta uma duplicidade interessante. Ao mesmo tempo é uma ciência e a experiência vivida por todos. Nesse segundo sentido é uma necessidade humana surgida como elemento fundamental na construção da identidade coletiva, de sentir-se fazendo parte do grupo social; então constroem-se laços de sociabilidade. Assim podemos remontar a civilizações antigas e também a grupos pré-históricos que criaram seus elos de sociabilidade a partir dos relatos dos mais velhos, inventados ou não, não faz diferença.

$\mathrm{Na}$ mediada em que se desenvolveram as civilizações e a sua capa- 
cidade de escrita, a história foi sendo cada vez mais importante, sobretudo para os grupos dominantes, que assim asseguravam suas justificativas para a dominação. E foram se justapondo o vivido e a ciência sobre o passado.

No entanto com a progressiva valorização da ciência moderna, geradora de soluções e de produtos, a história - tal como as demais ciências chamadas de humanas (Não são todas as ciências humanas?) - estava em descrédito, embora permanecesse vital na construção do Estado nacional, sendo considerada mais próxima das artes do que das ciências. Isso acarreta um demérito social e consequentemente econômico.

A proposta de A. Comte formulava uma valorização das ciências humanas e em especial a história. Para isso criou um método que a tornasse cientificamente aceita como produtora de conhecimento verdadeiro e passível de comprovação, atingindo, portanto, o status de ciência.

A história positivista se impôs como modelo científico ao longo do século XIX, no entanto alguns historiadores se incomodavam com seus postulados. Mas a institucionalidade da história comteana, dificultava uma crítica mais significativa.

Somente nas primeiras décadas do século XX essa crítica pode estruturar-se. O grupo mais significativo nesse percurso são os Annales $^{3}$, que entre outros feitos criou a revista na qual as novas formas de se produzir conhecimento histórico tiveram espaço. Dentre as críticas e novas propostas do grupo destacamos algumas 4 .

A história positivista parte do pressuposto de que a realidade é imutável, logo a verdade história é acessível plenamente. Já para a Nova História, a realidade é social ou culturalmente construída. O que aponta para diferentes perspectivas, de acordo com o historiador, suas fontes, suas questões, e sendo assim de suas explicações.

Enquanto no caso da história tradicional a temática abordada é a política; já para a Nova História "tudo é história"; ou seja, toda atividade humana tem uma construção no tempo, e deste modo uma explicação histórica. Esse processo de abertura empreendido pela história nova levou ao questionamento da cronologia tradicional, a qual apresentava uma narrativa dos acontecimentos. Fernand Braudel, membro da segunda geração dos Annales, propôs que trabalhássemos com o conceito de múltiplas temporalidades. Ele observou o processo histórico a partir da dialética entre mudanças e permanências. Indicou que as análises históricas busquem observar três durações

3 Em 1929, surgiu na França uma revista intitulada Annales d'Histoire Économique et Sociale, fundada por Lucien Febvre e Marc Bloch.

4 Cf. BURKE, Peter Abertura: a nova história, seu passado e seu futuro. In: BURKE, 1992, p. 7-37. 
temporais (curta, média e longa), ou seja, as relações entre os fatos, as conjunturas e as estruturas históricas ${ }^{5}$.

Outro aspecto a ser destacado é que para a história tradicional os sujeitos históricos são os 'grandes personagens'. Para a história nova todas as pessoas são sujeitos históricos, inclusive as pessoas comuns, também os sujeitos coletivos são sujeitos históricos, e há outros tipos também como um discurso ou uma ideia, por exemplo.

$\mathrm{Na}$ história tradicional as fontes documentais são necessariamente os documentos oficiais, uma vez que assim se comprova a informação e neles está a verdade. Ora a Nova História parte da ideia de que não é porque um documento é oficial que ele é a verdade. $O$ importante é a crítica profunda ao documento: quem produziu? Com que intenção? Quem preservou? Por que preservou? E avança na ideia do que pode ser uma fonte, tudo pode ser uma fonte histórica: iconografia, imprensa, relatos orais, dados quantitativos, documentos de todos os tipos. O importante é passar pelo crivo da crítica profunda.

Esses elementos do processo de transformação da área de história são suficientes para apontar o processo de renovação e de ampliação pelo qual os historiadores debateram ao longo do século XX. Como dito anteriormente, a história é ciência e também o nosso vivido, e consiste também em disciplina escolar; logo as mudanças pelas quais a história - enquanto ciência - passa, interferem na forma como é ensinada e, portanto em como vemos nossas próprias experiências.

Aqui dada à proposta de reflexão, destacaremos a questão do sujeito histórico. A história tradicional ao apontar apenas os grandes personagens e seus grandes feitos como temas históricos aparta-nos a todos do processo histórico. Somos meros mortais e espectadores da história. A nova história, ao ampliar a condição de sujeito histórico, nos coloca, a todos, como agentes no processo histórico, quer tenhamos ou não consciência disso. Logo a consciência nos leva a outro patamar de participação social ativa. Assim, o ensino de história sob essa perspectiva passa a outro aspecto da história ciência: sua função social e política. A formação de crianças e jovens que se reconhecem no processo histórico, uma vez que seus antepassados são sujeitos daquela história serão provavelmente cidadãos mais ativos.

A cidadania passiva, muito conveniente no intento conservador de manutenção do status quo vigente, explica a dificuldade de implantação da história nova na escola brasileira. Há de se destacar ainda que o ensino da história tradicional privilegia a memorização, enquanto mudança conceitual

5 Para maior detalhamento cf. VIEIRA, Rosângela de Lima. Fernand Braudel: a relação do método historiográfico e o conhecimento histórico. 10/10/2002. Tese (Doutorado em História) - Faculdade de Ciências e Letras, Universidade Estadual Paulista. Assis, 26 set. 2002. 
a nova história, dado seu propósito, reformula seu caráter pedagógico então pede compreensão, explicação.

Feita essa sintética exposição da autorreflexão da história, vamos exemplificar a partir de duas estruturas históricas na nossa sociedade: o machismo e o racismo.

\section{Machismo estrutural}

Iniciamos refletindo sobre o processo histórico da construção da Declaração dos Diretos do Homem e do Cidadão. É de conhecimento que a construção da proposta, sua discussão e aprovação ocorrem na conjuntura da Revolução Francesa. Muito embora seja razoavelmente comum simplesmente se indicar a data de sua promulgação pela Assembleia Nacional Constituinte Francesa, em 26 de agosto de 1789. Quando me reporto ao processo histórico da declaração almejo mais do que a data, mas como já referi, a conjuntura. Interessa-me resgatar os múltiplos sujeitos envolvidos para a sua elaboração e aprovação; se houve propostas dissonantes não aprovadas etc; mais especificamente desejo fazer uma pergunta: essa era a única proposta?

Em pesquisa é possível descobrimos que a resposta é NÃO. Houve também a proposta de Olympe de Gouges ${ }^{6}$. Ela é autora da Declaração dos Direitos da Mulher e da Cidadã7, de 1791. Certamente para muitos será surpresa ter conhecimento de ter existido tal pessoa, bem como o próprio documento. A Declaração de Gouges tem como preâmbulo

Mães, filhas, irmãs, mulheres representantes da nação reivindicam constituir-se em uma assembleia nacional. Considerando que a ignorância, o menosprezo e a ofensa aos direitos da mulher são as únicas causas das desgraças públicas e da corrupção no governo, resolvem expor em uma declaração solene, os direitos naturais, inalienáveis e sagrados da mulher. Assim, que esta declaração possa

6 Em Montauban (Sul da França) em 1748, nasce Marie Gouze, filha açougueiro e criada sob as convenções da França setecentista. Aos 18 anos, mãe e viúva, se vê livre para expressar suas ideias e adota o pseudônimo Olympe de Gouges. Anos depois se muda para Paris, onde participou ativamente da vida política e cultural. Fiel leitora de Rousseau, inspirada pelas ideias libertárias da França pré-revolucionária, Olympe se dedica intensamente à escrita - atividade que levaria até os últimos dias de sua vida e que lhe causaria muitos problemas. Conquistou inimizades e escandalizou os mais conservadores, porém jamais deixou de defender seus ideais libertários. Em 1791, redigiu a Declaração dos direitos da mulher e da cidadã, reivindicando a igualdade entre os sexos e o direito ao voto. Produziu planfletos e petições em uma grande variedade de frentes de luta, incluindo a escravidão, em que lutou para sua extirpação. Opõe-se abertamente a Robespierre e acaba por ser guilhotinada em 1793, condenada como contra revolucionária e denunciada como uma mulher "desnaturada”. In: SALGADO, Luiza M.; SOUSA, Aída C. R. de. Antologia de Escritoras do século XVIII. Biografias. Olympe de Gouges. Disponível em: https://mnemosineantologiasdotcom.files.wordpress.com/2015/07/gouges_bio.pdf. Acesso em: 20 jul. 2020.

7 Este documento foi proposto à Assembleia Nacional da França, durante a Revolução Francesa (1789-1799). Disponível na Biblioteca Virtual de Direitos Humanos da USP. Declaração dos Direitos da Mulher e da Cidadã. 
lembrar sempre, a todos os membros do corpo social seus direitos e seus deveres; que, para gozar de confiança, ao ser comparado com o fim de toda e qualquer instituição política, os atos de poder de homens e de mulheres devem ser inteiramente respeitados; e, que, para serem fundamentadas, doravante, em princípios simples e incontestáveis, as reivindicações das cidadãs devem sempre respeitar a constituição, os bons costumes e o bem estar geral.

Em consequência, o sexo que é superior em beleza, como em coragem, em meio aos sofrimentos maternais, reconhece e declara, em presença, e sob os auspícios do Ser Supremo, os seguintes direitos da mulher e da cidadã [.... ${ }^{8}$

Dentre muitos aspectos do documento, vamos destacar a ideia de que todos os membros do corpo social têm direitos e deveres, e mais ainda quando isso é proposto pelas mulheres. Que civilização teríamos construído com direitos iguais entre homens e mulheres?

No entanto nem sabemos que houve a proposta; claro, mulheres não são sujeitos históricos, na história tradicional dos 'grandes homens'; logo, esse documento não se constituiu num tema escolar. Aliás, como inúmeros outros. No caso Brasil, por exemplo, poderíamos recordar os projetos de abolição da escravatura formulados desde a década de 1830 completamente ignorados da educação escolar, cujo conhecimento nos daria condições para explicarmos as vertentes políticas do período imperial e suas estratégias conservadoras.

Há na Declaração dos Direitos da Mulher e da Cidadã 16 artigos e uma conclusão:

Mulher, desperta. A força da razão se faz escutar em todo o Universo. Reconhece teus direitos. O poderoso império da natureza não está mais envolto de preconceitos, de fanatismos, de superstições e de mentiras. A bandeira da verdade dissipou todas as nuvens da ignorância e da usurpação. $\mathrm{O}$ homem escravo multiplicou suas forças e teve necessidade de recorrer às tuas, para romper os seus ferros. Tornando-se livre, tornou-se injusto em relação à sua companheira? .

E ao final do documento apresenta uma proposta de um Formulário para um Contrato Social entre Homem e Mulher, do qual destaco a proposta de que todos têm o direito ao nome do pai e da mãe, seja legítimo ou não. Ora, quanto tempo demoramos para aprovar isso em nosso país ${ }^{10}$ ?

Por fim há de se destacar ainda a reação do 'revolucionários' à demanda feminina. Os inimigos vieram de todas as partes desde Robespierre até Marat. Olympe de Gouges foi condenada à guilhotina, a sentença "[...] acu-

8 Idem.

9 O final do trecho aponta para uma triste realidade: escravos uma vez libertos, subjugam suas mulheres.

10 Em 31 de março de 2015 entrou em vigor a Lei n. ${ }^{\circ}$ 13.112, que altera os itens $1^{\circ}$ e $2^{\circ}$ do art. 52 da Lei no 6.015 , de 31 de dezembro de 1973 (Lei de Registros Públicos), para permitir à mulher, em igualdade de condições, proceder ao registro de nascimento. Cf. em: https://jus.com.br/artigos/37787/a-nova-lei-que-permite-a-mae-registrar-o-filho-no-cartorio-e-a-indicacao-da-paternidade. Acesso em: 20 jun. 2020. 
sou-a de "ter querido ser um homem de Estado e ter esquecido das virtudes de seu próprio sexo", ela foi guilhotinada em 3 de novembro de 1793." (DINIZ, 2010, p. 39)

A Revolução Francesa pregou a liberdade, a igualdade e a fraternidade, entre os homens, é claro!

E um decreto de 1795 da Assembleia Nacional determina:

Decreta-se que todas as mulheres se retirarão, até ordem contrária, aos seus respectivos domicílios. Aquelas que, uma hora após a publicação do presente decreto, estiverem nas ruas, agrupadas em número maior que cinco, serão dispersadas pela força das armas e presas até que a tranquilidade retorne a Paris. (DINIZ, 2010, p. 39)

Vemos, então, que a situação de intranquilidade em plena Revolução, para os jacobinos e girondinos na fase chamada pelos historiadores 'de terror' se deve em parte pelo comportamento feminino. Tão grave quanto a esses fatos históricos, é que essa história não foi contada. Somente no final do século passado e no atual século a história de Olympe de Gouges começou a ser desvendada na conjuntura de rever a história e a ação das mulheres nela ${ }^{11}$.

Sua luta pela igualdade de direitos entre homens e mulheres estava em sintonia com a luta contra o racismo. Em 1788, Olympe escreveu "Reflexões sobre os negros", posicionando-se contra a escravidão. A autora denuncia a injustiça e o preconceito que a população negra sofria, mesmo que em uma época de ideias iluministas. Além de refletir sobre esses temas, Gouges critica a Comédie Française, instituição teatral, por não permitir que uma de suas peças de teatro fosse representada ao público, já que continha uma crítica à discriminação racial. (DRIGO; PAGNOSSI, 2018, p. 283)

\section{Racismo estrutural}

Neste tópico, gostaria de demonstrar que a função social e política do conhecimento histórico é a questão racial. Durante a pandemia de Covid-19 os movimentos antirracistas explodiram a partir de casos de homicídios ${ }^{12}$ praticados por policiais racistas nos EUA.

Os movimentos tomaram as ruas, apesar da necessidade de isolamento social imposto pela pandemia. As pessoas superaram seus temores pessoais de contaminação para exigirem o fim do racismo estrutural. Partindo

11 SCOTT, Joan. História das Mulheres. In: BURKE, 1992, p. 63 a 95.

12 Assassinato de George Floyd em 25 de maio de 2020, depois que Derek Chauvin, então policial de Minneapolis, ajoelhou-se no pescoço dele durante oito minutos e quarenta e seis segundos, enquanto estava deitado de bruços na estrada. 
da ideia de que não basta não ser racista, mas é preciso ser antirracista, tal postura se deu pela consciência de um cruzamento entre a percepção estrutural dessa realidade sócio-histórica e a necessidade de assumir a parcela de sujeito do processo histórico. Os movimentos passaram a estar cotidianamente nas mídias; artistas e esportistas manifestaram-se mantendo o tema em pauta por semanas. E nos EUA, na Europa e por todo lado vimos estátuas de escravistas caírem. Gosto muito dessa imagem, - apesar de muito controversa - pois demonstra o povo retomando seu caráter de sujeito da história. Não querer continuar homenageando este ou aquele personagem do passado é assumir ativamente a história do presente.

O racismo é um fenômeno histórico de longa duração, ou na conceituação de Fernand Braudel, uma estrutura histórica. Caracteriza-se por um processo multissecular, de 500 anos, que compõe o conjunto da sociedade, seja no aspecto social, político, econômico, cultural, jurídico, policial... A superação de estruturas históricas exige mudanças estruturais, mas também - por estarem arraigadas no cotidiano - necessitam da tomada de consciência, da mudança de comportamentos coletivos e individuais.

O conhecimento histórico tem contribuído para essa consciência. Até poucas décadas atrás os estudos sobre a escravidão e a abolição da escravidão apontavam uma história de brancos para brancos. A revisão ocorreu a partir do conceito de 'história do ponto de vista dos de baixo' colocando a necessidade dos múltiplos sujeitos históricos na superação de uma história dos opressores ${ }^{13}$.

No caso da história do Brasil, por exemplo, há uma contribuição significativa das pesquisas de Maria Helena Machado, entre outros. A historiadora estuda os movimentos dos escravizados - principalmente a partir da década de 1870 na região de Campinas (SP) - e concluiu que, embora os movimentos não apontassem um risco concreto à permanência da escravidão, surtiram um efeito nas populações urbanas. E estas passam a pressionar a Assembleia; o que em última instância, favoreceu a aprovação da Lei Áurea ${ }^{14}$.

Expondo o crescimento do medo e do pânico das elites nacionais nas décadas que precederam o ano de 1888, em virtude do aumento das revoltas e rebeldias escravas, Maria Helena Machado ressalta a condição daqueles escravizados enquanto sujeitos do processo histórico. Também os vários casos em que os escravos levaram seus senhores aos tribunais na busca de direitos legais constituíram-se num elemento importante nesse processo de esgota-

13 SHARPE, Jim. A história vinda de baixo. In: BURKE, 1992, p. 39-62.

14 Cf. VIEIRA, R. L. O Golpe Militar de 1964 na perspectiva braudeliana: fato, conjunturas e estruturas históricas. In: BRABO, Tânia S. A. M. (org.). Direitos humanos, educação e participação popular: 50 anos do Golpe Militar. Marília: Oficina Universitária, São Paulo: Cultura Acadêmica, 2014, p. 65-87. 
mento do escravismo.

Trata-se do 'haitianismo' como se refere João José Reis, como pano de fundo, facilitou a aceitação da inevitabilidade da abolição como o mal menor. Porém, para ele, a elite escravocrata ainda era maioria e somente a pressão dos fatos ou do mito exemplar de São Domingos foram capazes de possibilitar a aprovação da Lei Áurea.

\begin{abstract}
Não fosse a ação dos escravos rebeldes, a escravidão teria sido um horror maior do que foi, pois eles marcaram limites além dos quais seus opressores não seriam obedecidos. Embora fossem derrotados tantas vezes, os escravos se constituíam em força decisiva para a derrocada final do regime que os oprimia. Tivessem eles se adequado aos desígnios senhoriais, o escravismo brasileiro talvez tivesse adentrado o século XX. (REIS, 2000, p. 262)
\end{abstract}

A Lei de 1888, como sabemos, não garantiu direitos aos escravizados libertos, jogando uma multidão à margem da sociedade brasileira. Os fazendeiros preferiam assalariar os imigrantes brancos e aos ex-escravos couberam os trabalhos mais pesados e sujos que outros homens livres e pobres não aceitavam fazer. No entanto, apesar de uma abolição excludente, para ela ocorrer as pressões vieram de muito lugares, inclusive da senzala. Reconhecer nossos antepassados como sujeitos históricos, cujas ações interferiram no processo histórico é fundamental na construção de uma sociedade de sujeitos ativos e conscientes.

O legado de nossos antepassados nos impele a não os decepcionar. Saber que lutaram e até morreram por seus ideais exige de nós a tomada de consciência e assumir nossas responsabilidades no processo histórico. Lição histórica de uma história repensada para a pluralidade humana, uma pluralidade de sujeitos históricos ativos.

\title{
Considerações finais
}

Contribuir para pensar e construir relações sociais cujo cerne seja a dignidade humana tem muitos aspectos um deles é a possibilidade de reconhecer-se sujeito de direitos, ora para isso reconhecer-se sujeito histórico - aquele que participa do processo histórico e cujas ações interferem nele constitui-se num primeiro passo.

No entanto isso não pode ocorrer de forma ingênua, num procedimento alienado das estruturas históricas, para não causar a impressão de incapacidade de mudanças. Já que o voluntarismo não será suficiente para uma rápida transformação das estruturas multisseculares.

Uma metáfora nos ajuda a entender: suponhamos que as estruturas históricas sejam largas avenidas de múltiplas faixas de trânsito e que a toma- 
da de consciência da condição de sujeito histórico seja uma pessoa tentando atravessar essa avenida. Temos então um entrecruzamento: uma avenida e um cidadão. O primeiro passo é reconhecer a avenida: há passarela? Se não houver: quantas são as faixas de trânsito, tem ou não faixa de pedestres e sinal de trânsito? O movimento de veículos é ou não intenso? Apresenta canteiro central como obstáculo ou não? Uma pessoa observando essa realidade poderá fazer a travessia dessa estrutura sem alterá-la. No entanto, uma multidão poderá invadi-la, impedindo a passagem dos veículos. Essa avenida deixará de ser o que é, mesmo que momentaneamente - enquanto estiver ocupada pela multidão.

Esse entrecruzamento entre uma avenida e a multidão que a atravessa é o enfrentamento de estruturas históricas de longa duração. Se o fato ocorrer muitas vezes, e simultaneamente outros fatos forem suscitados por aquele, como uma mudança na lei que rege o funcionamento da avenida - como, por exemplo, no caso empreendido a partir da morte de George Floyd, uma mudança no conceito de polícia e de suas formas de abordagem - pode ocorrer o início de um processo de mudança estrutural. Que se confirmará com novas práticas sociais e muitas outras ações. O que certamente não se efetivará num movimento retilíneo e uniforme, uma vez que os conservadores e reacionários também agirão no sentido de impedir as mudanças.

Daí a importância da consciência que não basta não ser racista, é preciso ser antirracista, não basta não ser machista, é preciso ser antimachista, não basta não ser consumista, é preciso ser anticonsumista, não basta não ser homofóbico, é preciso ser anti-homofóbico, não basta não ser um poluidor contumaz, é preciso defender o meio ambiente, economizar água, promover coleta seletiva..., enfim ser um sujeito ativo consciente da mudança.

Relevante recordar Immanuel Wallerstein (2007) aqui, cuja reflexão sobre o intelectual nos impele a agir conscientemente,

O intelectual funciona necessariamente em três níveis: como analista na busca da verdade; como pessoa moral na busca do bem e do belo; e como pessoa política na busca pela unificação do verdadeiro com o bom e o belo. (p. 119)

E a assumir nossas responsabilidades científicas, éticas e morais.

Duas das maiores chagas contra a dignidade humana de nosso tempo: machismo e racismo são fenômenos históricos de longa duração, ou seja, constituem-se em estruturas históricas do capitalismo ${ }^{15}$. A consciência dessa característica é fundamental para sua superação. A dignidade humana plena

15 Sobre o machismo e o racismo, como estruturas históricas do capitalismo, consultar VIEIRA, R. L. A ilusão da democracia no capitalismo histórico. Perspectivas, São Paulo, v. 52, p. 137-149, jul./dez. 2018. Disponível em: https:// periodicos.fclar.unesp.br/perspectivas/article/view/13237/8723. Acesso em: 20 jul. 2020. 
somente será alcançada quando ambas forem extirpadas. Igualdade, liberdade e solidariedade são pilares indissociáveis, logo todas as lutas são coletivas.

O entrecruzamento do reconhecimento das estruturas históricas, que embora seja de longa duração, são históricas - ou seja, passíveis de mudança já que são construções humanas - com o autorreconhecimento de sujeito histórico, portanto agente de mudança, se constitui num despertar para as transformações profundas que nossa civilização demanda.

O percurso aqui empreendido buscou demonstrar que a compreensão da pluralidade temporal e de sujeitos históricos nos assinalam que nosso tempo é agora, mas também o de longa duração está aqui, então o que fazemos interfere no presente, no futuro e no passado no sentido de alterar as estruturas históricas.

Importante ainda destacar que tais mudanças se operam muito lentamente, por isso não podemos desanimar quando eventualmente parecemos estagnados ou até retrocedendo. Tudo nesse nosso globo azul em movimento constante se modifica. Geralmente não percebemos dada a lentidão e parece que 'sempre foi assim e sempre será' como se diz no senso comum. No entanto quando ouço isso costumo responder com um exemplo: será que os oprimidos pelo Império Romano imaginavam seu fim? Seus algozes pareciam eternos certamente. Gerações e gerações nasceram e morreram naquelas estruturas de opressão. Contudo hoje restam as ruínas de um Império para nos lembrarmos dos abusos impetrados por aquela sociedade.

Outro exemplo para elucidar é pensarmos se a população europeia dos séculos XIV a XVI sabiam que viviam uma das maiores transformações de sua civilização, o Renascimento? Período em que além das artes, desenvolveu a ciência, colocou o homem no centro, reviu sua própria religião, ocupou os oceanos e outros continentes..., enfim esboçou a modernidade. Certamente pouquíssimos perceberam em seu cotidiano o que se operava, mesmo assim isso se sucedia.

Nesse exercício de imaginação, se o Renascimento foi o que foi, sem que os sujeitos daquele processo histórico percebessem, agora com a possibilidade de conhecimento e, sendo assim, conscientes da condição de sujeitos, podemos tomar para todos nós a possibilidade de construção de uma sociedade na qual a dignidade humana só seja plena se for para todos.

Mudanças e permanências históricas são siamesas; rupturas totais com as estruturas históricas ocorrem num processo histórico muito lentamente e em movimentos de avanços e recuos, daí a importância de sujeitos históricos ativos, conscientes e persistentes.

Indica, portanto, de forma imperiosa a necessidade de ensinar a pensar historicamente, ou seja, a pensar o(s) humano(s) no tempo. Eis o papel 
social e político da história: a superação de um conhecimento histórico conservador e passar a contribuir para a construção da dignidade humana a partir do conceito de sujeito histórico e de sujeitos históricos coletivos. Seja na pesquisa, seja no ensino da disciplina, a história pode promover a percepção de que o pouco que a humanidade evoluiu na conquista da dignidade humana - em oposição a várias formas de opressão, violência e exploração - foi como resultado de ações coletivas, de múltiplos sujeitos.

Minha experiência como professora de ensino desde a escola básica ao universitário, na formação de professores, minhas pesquisas e reflexões apontam para o salto de qualidade, na formação dos jovens, a experiência com a história estudada a partir dos múltiplos sujeitos e da análise dos processos históricos de longa duração. Nesse sentido desejo opor-me enfaticamente ao uso recorrente de alguns termos como: palco ou cenário, atores sociais e outros semelhantes que apontam para a ideia de teatro social com roteiro prévio. Não temos um roteiro. Temos um processo histórico, com estruturas históricas multisseculares a serem superadas por sujeitos históricos conscientes, ativos conscientes da lentidão das mudanças; que se operam cotidianamente e não ocorrem num movimento retilíneo e uniforme, mas em oposição à opressão, frente às reações conservadoras e reacionárias.

E nesse sentido é indispensável que os estudantes, sejam sujeitos de direitos de sua própria aprendizagem, como primeiro passo no sentido de reconhecer a si e aos outros como sujeitos da construção de sua própria dignidade e da dos outros.

Por tudo aqui exposto defendo que a história tem muito a contribuir. Ensinar história me dá esperança, estar com jovens me dá esperança, ensinar história aos jovens me dá muita esperança. Como Cora Coralina, reconheço tem muito chão, nos meus olhos também, mas esperançar é defender que

Vidas negras importam, vidas das mulheres importam, vidas humanas, dos animais, das plantas... todas as vidas importam e devem ser dignas! 


\section{Referências}

BIBLIOTECA VIRTUAL DE DIREITOS HUMANOS DA USP - Declaração dos direitos da mulher e da cidadã - 1791. Disponível em: http://www.direitoshumanos. usp.br/index.php/Documentos-anteriores-\%C3\%A0-cria\%C3\%A7\%C3\%A3oda-Sociedade-das-Na\%C3\%A7\%C3\%B5es-at\%C3\%A9-1919/declaracao-dosdireitos-da-mulher-e-da-cidada-1791.html. Acesso em: 20 jul. 2020.

BURKE, Peter "Abertura: a nova história, seu passado e seu futuro". In: BURKE, Peter. (org.). A escrita da história. Novas perspectivas. São Paulo: Editora Unesp, 1992. p. 7-37.

DINIZ, Maria José Pereira. Ações do movimento feminista pelo fim da violência doméstica contra a mulher no estado de Pernambuco: conquista e desafios. Recife: UFPe 2010. Disponível em: https://repositorio.ufpe.br/bitstream/123456789/9419/1/arquivo337_1.pdf. Acesso em: 20 jul. 2020.

GOUGES, Olympe de. Reflexões sobre os negros. Tradução de Jasmim Sedie e Nádia Carrasco Pagnossi, Revista História e Ensino, Londrina, v. 24, n. 1, p. 283-288, 2018. Disponível em: http://www.uel.br/revistas/uel/index.php/histensino/article/view/32231. Acesso em: 20 jul. 2020.

MACHADO, Maria Helena. Crime e escravidão - trabalho, luta e resistência nas lavouras paulistas. São Paulo: Brasiliense, 1987.

MACHADO, Maria Helena. O plano e o pânico. Os movimentos sociais na década da abolição. Rio de Janeiro: Editora UFRJ, São Paulo: EDUSP, 1994.

REIS, João J. Nos achamos em campo a tratar da liberdade: a resistência negra no Brasil oitocentista. In: MOTA, Carlos G. (org.). Viagem incompleta: a experiência brasileira (1500-2000). São Paulo: Editora SENAC, 2000. p. 241-263.

SCOTT, Joan História das Mulheres. In: BURKE, Peter. (org.). A escrita da história. Novas perspectivas. São Paulo: Editora Unesp, 1992. p. 63 a 95.

SHARPE, Jim A história vinda de baixo. In: BURKE, Peter. (org.). A escrita da história. Novas perspectivas. São Paulo: Editora Unesp, 1992. p. 39-62.

WALLERSTEIN, Immanuel. O universalismo europeu: a retórica do poder. Trad. Beatriz Medina. São Paulo: Boitempo, 2007 
